\title{
Duplication Cysts in the Oesophagus and Pylorus of a Juvenile Grey Seal (Halichoerus grypus): A Case Report
}

\author{
Andrew Y Kushnir, Tiffany Ng, David Kilroy, and Hanne Jahns*
}

\begin{abstract}
Duplication cysts of the gastrointestinal tract in mammals are rare congenital anomalies that arise during embryonic development. Finding these cysts in a juvenile Grey seal is also a rare observation. We report here a coincidental finding of two gastrointestinal duplication cysts in a 4-week-old female Grey seal, which was found on a beach on the East coast of Ireland. Gross anatomical features of the esophagus and pylorus together with the histological features of the cyst are presented.
\end{abstract}

Key words: Seal, Stomach, Cyst, Gastrointestinal tract, Gross Anatomy.

\section{INTRODUCTION}

Duplication cysts of the gastrointestinal tract in mammals are rare congenital anomalies that arise during embryonic development. These are seen as elongated, tubular or spherical cystic masses in the wall of the gastrointestinal tract, usually unilocular and fluid filled. Multiple septations and thick content may be observed. ${ }^{1}$ Anatomical location and size of duplication cysts determines the associated clinical signs, if any occur. Oesophageal duplication cysts have been reported in humans, ${ }^{2}$ domestic species ${ }^{3-8}$ and in a cynomolgus macaque. ${ }^{9}$ Dysphagia and regurgitation are the most frequent clinical signs associated with oesophageal duplication cysts in humans and nonhuman species..$^{2-7}$ Pyloric duplication cysts have been reported in humans but to the authors' knowledge, not yet in other species. Persistent vomiting is the most frequent clinical sign associated with pyloric duplication cysts and other duplication cysts near the pylorus in humans due to gastric outflow obstruction. ${ }^{10-13}$ This case report describes the occurrence of two gastrointestinal duplication cysts in a grey seal pup. To the author's knowledge, this is the first report of the occurrence of duplication cysts in the gastrointestinal system of the Grey seal.

\section{CASE REPORT}

A 4-week-old female Grey seal (Halichoerus grypus) was found on a beach on the East coast of Ireland. At presentation it weighed $11.5 \mathrm{~kg}$ (Emaciated) and was bright, alert and responsive. It was brought to a seal sanctuary where it was initially tube-fed $300 \mathrm{ml}$ of an Electrolyte Solution (ELS) using a silicon tube with an internal diameter of $8 \mathrm{~mm}$, external diameter of $12-14 \mathrm{~mm}$. Placement of the tube into the stomach was confirmed by listening for borborygmi prior to administration; approximately $50 \mathrm{ml}$ was regurgitated as the tube was removed. Daily tube-feedings

Cite this article : Kushnir AY, Tiffany Ng, Kilroy D, Jahns H. Duplication Cysts in the Oesophagus and Pylorus of a Juvenile Grey Seal (Halichoerus grypus): A Case Report. BEMS Reports. 2019;5(1):10-12. of $350 \mathrm{ml}$ of ELS combined with a blended mixture of herring and salmon oil ("fish soup") occurred for the first week, four times daily. Every $24 \mathrm{hrs}$ the proportion of "fish soup" was increased by $25 \%$. The seal consistently regurgitated $15-100 \%$ of feed upon tube removal twice daily for the first few days and two separate episodes of vomiting occurred sometime after tube feeding on the fourth day.

Eventually the seal pup responded to the treatment and was able to eat fish by itself without regurgitation after a week and gained some weight. Two weeks later however, the pup stopped eating, just chewed the fish and didn't swallow any contents. Regurgitation recurred with tube feeding and despite supportive treatment, the seal died two days later and was submitted for post mortem examination to the University Veterinary Hospital, University College Dublin.

\section{Post Mortem Examination}

The body condition of the seal pup was poor with a ventral abdominal blubber of $2 \mathrm{~mm}$ thickness and body weight $12.3 \mathrm{~kg}$. The lungs were diffusely mottled with dark and bright red areas and were congested. Moderate amounts of food contents were found in the caudal trachea and bronchi. At the distal oesophagus, there was a $5.5 \mathrm{~cm} \times 5 \mathrm{~cm}$ large, soft fluid filled cyst, $5 \mathrm{~cm}$ proximal to the cardia (Figure 1 ). The cyst contained $50 \mathrm{ml}$ of white, mucoid fluid and did not communicate with the lumen of the oesophagus (Figure 2 ). At the pylorus, a $4 \mathrm{~cm} x 4 \mathrm{~cm}$ polypoid multi-cavitated mass was found within the gastric wall (Figure 3 ). The cavities contained dried, grey-yellow material and did not communicate with the gastric lumen. The stomach was empty and little digesta present in the intestines. Scant faeces were present in the rectum.

Histopathological examination of the oesophageal cyst showed a large cavity lined by stratified squa(C) 2019 Phco

2019 Phcog.Net. This is an open-access article distributed under the terms of the Creative Commons Attribution 4.0 International license. 


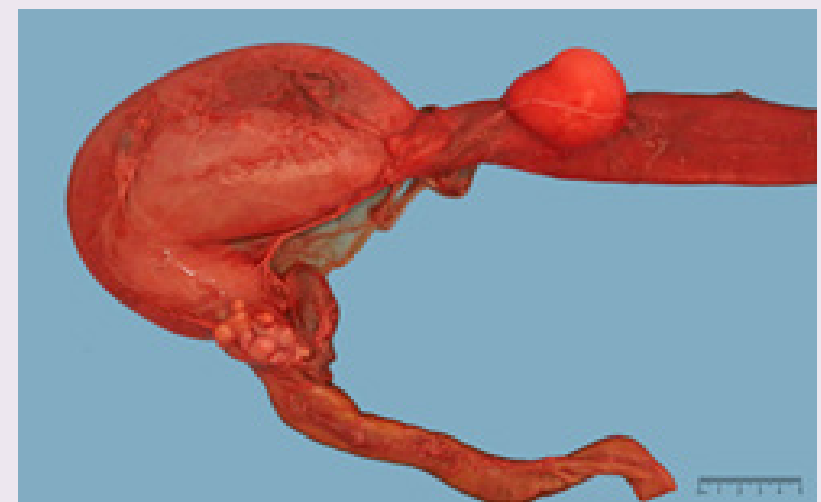

Figure 1: Juvenile Seal, Upper Gastrointestinal Tract; A Large Cyst was Observed in the Wall of the Distal Oesophagus and Smaller Multiple Cysts were Seen at the Level of the Pylorus.

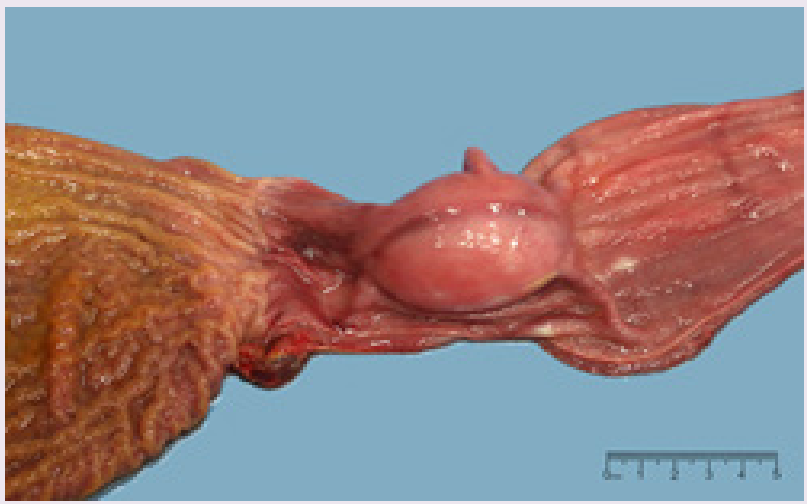

Figure 2: Juvenile Seal, Opened Distal Oesophagus and Proximal Stomach; The Cyst did not Communicate with the Lumen of the Oesophagus.

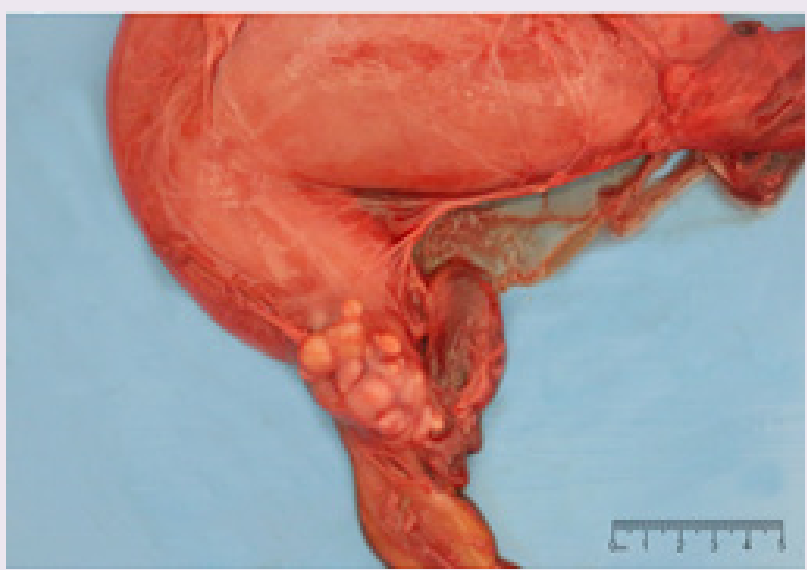

Figure 3: Juvenile Seal, Distal Stomach and Duodenum; Large Polypoid Multicavitated Cystic Mass at the Level of the Pylorus.

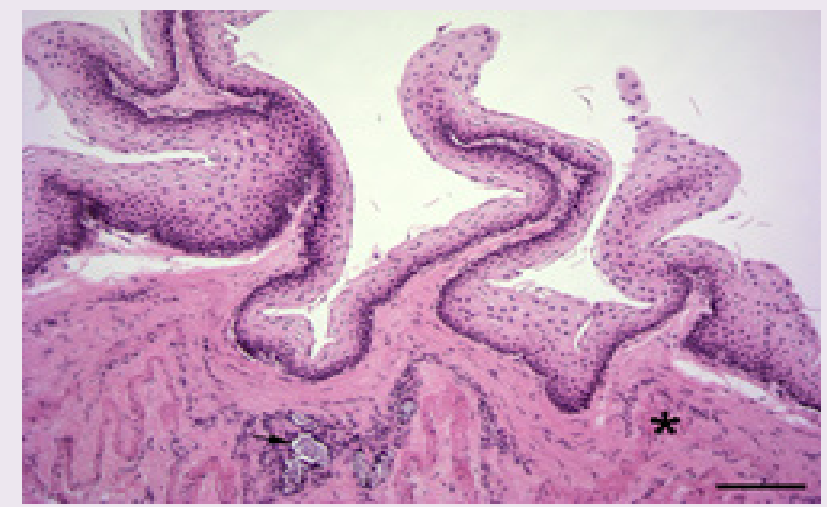

Figure 4: Seal, Oesophageal Duplication Cyst; the Cyst is Lined by Stratified non-Keratinized Squamous Epithelium. This is Supported by the Submucosa, Few Small Dilated Mucoid Glands (Arrow) and the Tunica Muscularis $\left({ }^{*}\right)$. Haematoxylin and Eosin stain; bar $=100 \mu \mathrm{m}$.

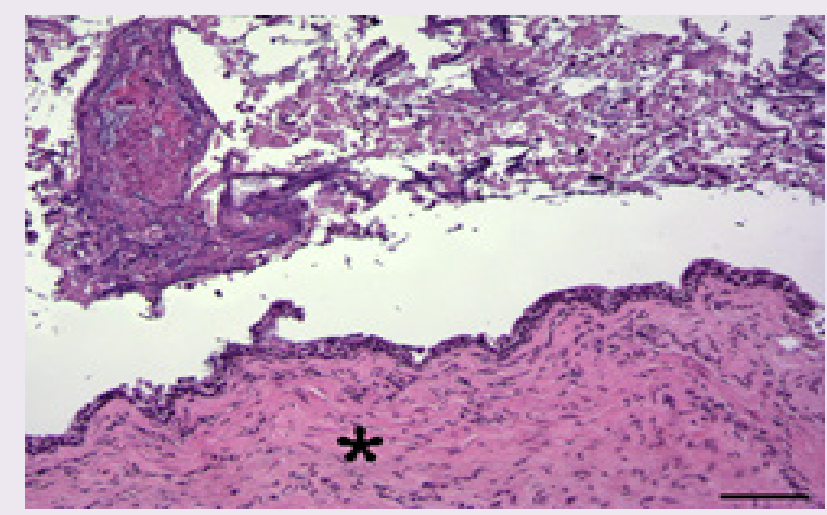

Figure 5: Seal, Pylorus Duplication Cyst; the cyst is Lined by a Layer of High Columnar Epithelial Cells Often Flattened and Attenuated. Smooth muscle is observed as a tunica muscularis $(*)$. The cysts contains sloughed epithelial cells, mucin and cell debris. Haematoxylin and Eosin stain; bar = $100 \mu \mathrm{m}$.

mous epithelium and surrounded by submucosa and smooth muscle continuous to the tunica muscularis of the oesophagus (Figure 4). Few small remnant cystic glands were occasionally seen at the tunica muscularis. The multi-cavitated mass at the pylorus consisted of multiple cysts lined by columnar to cuboidal epithelium and some mucous containing cells which resembled enterocytes (Figure 5). The lumen contained large amounts of sloughed epithelial cells, mucin and cell debris. Within the lungs there was marked congestion and presence of large amounts of bright eosinophilic amorphous material in the alveolar spaces (Oedema). The bronchi and bronchioles contained granular amphophilic and eosinophilic material (food).

Based on the gross and microscopic features a diagnosis of gastrointestinal duplication cysts at the level of the oesophagus and the pylorus was made. There was marked aspiration of food present at post mortem examination but in the absence of inflammation in the lungs, this likely happened agonally. Apart from emaciation there was no evidence of any underlying disease that could explain the death of the seal.

The presence of the cysts and subsequent regurgitation and vomiting likely debilitated the animal and may have led to the stranding. 


\section{DISCUSSION}

This is the first report, to our knowledge, of gastrointestinal duplication cysts in the Grey seal. Gastrointestinal duplication cysts are rare congenital anomalies that arise during embryonic development due to either incomplete recanalization or atypical blastogenesis of the primitive foregut. $^{14}$ The prevailing theory regarding duplication cysts suggests that errors in recanalization occur during the fifth to sixth week of gestation, when epithelial proliferation obliterates the lumen of the associated gastrointestinal tract. Vacuoles form and coalesce to reestablish the lumen of the tract. Failure of these vacuoles to coalesce may lead to the development of duplication cysts. ${ }^{15}$

Palmer's pathological criteria for duplication cysts is often used to define duplication cysts and has three criteria: (1) the lesion is within or attached to the gastrointestinal wall; (2) the cyst wall has one or two layers of smooth muscle (Differentiating them from simple cysts); and (3) the cyst lining contains epithelium of the gastrointestinal tract (Squamous, cuboidal, ciliated or pseudostratified). ${ }^{16}$

Oesophageal Duplication Cysts (ODCs) account for 10-15\% of gastrointestinal duplication cysts in humans. ${ }^{2}$ In the majority of human cases (80-90\%), they present as extramural cysts and do not communicate with the oesophageal lumen. ${ }^{17}$ Dysphagia and regurgitation are the most frequent clinical signs of ODCs due to compression of the oesophageal lumen.

Pyloric Duplication Cysts (PDCs) account for 2-3\% of gastrointestinal duplication cysts in humans. ${ }^{18}$ Duplication cysts at the level of or near the pylorus are usually symptomatic in children and asymptomatic in adults. ${ }^{19}$ The usual presentation of duplication of the pylorus in neonates is vomiting, weight loss and bleeding from the alimentary tract. ${ }^{19}$

The juvenile seal in this report was found severely emaciated $(11.5 \mathrm{~kg}$ body weight) at approximately 4 weeks of age. At birth, grey seal pups weigh an average of $16 \mathrm{~kg}$, suckle for 16-21 days ${ }^{20}$ and weigh between 40 and $50 \mathrm{~kg}$ when weaned. During the immediate postweaning period pups lose 0.4 to $0.6 \mathrm{~kg}$ bodyweight daily. ${ }^{21-23}$

While malnutrition/starvation is the primary cause of live-strandings of juvenile seals ${ }^{24}$ the emaciation at stranding and the seal's failure to thrive even after responding to treatment at the sanctuary are most likely due to the symptomatic effects of the combined oesophageal and pyloric duplications cysts.

Congenital anomalies are rarely described in free-ranging marine mammals and the number of young or preweaned seal pups affected is reported between $0 \%$ in harbour seals, ${ }^{25} 1.8 \%$ in Northern elephant seals ${ }^{26}$ and $5.7 \%$ in Northern fur seals. ${ }^{27}$

In conclusion, congenital anomalies as reported in other mammals can occur in Grey seals, although rare and should be considered a cause of stranding. Here congenital duplication cysts of the gastrointestinal tract were reported in a Grey seal presenting with emaciation, dysphagia, regurgitation and vomiting.

\section{CONCLUSION}

In conclusion, congenital anomalies as reported in other mammals can occur in Grey seals, although rare and should be considered a cause of stranding. Here congenital duplication cysts of the gastrointestinal tract were reported in a Grey seal presenting with emaciation, dysphagia, regurgitation and vomiting.

\section{CONFLICT OF INTEREST}

The authors declare no conflict of interest.

\section{ABBREVIATIONS}

ODCs: Oesophageal Duplications Cysts; PDCs: Pyloric Duplication Cysts.

\section{REFERENCES}

1. Segal SR, Sheman NH, Rosenberg HK. Ultrasonographic features of gastrointestinal duplications. J Ultrasound Med. 1994;13(11):863-70.

2. Liu R, Adler DG. Duplication cysts: Diagnosis, management and the role of endoscopic ultrasound. Endosc Ultrasound. 2014;3(3):152-60.

3. Gabor LJ, Walshaw R. Esophageal duplication cyst in a dog. Vet Pathol. 2008;45(1):61-2

4. Foglia A, DelMagno S, Pietra M, Cola V, Joechler M, Morini M, et al. Surgical Treatment of a thoracic esophageal duplication cyst causing recurrent dysphagia in an adult dog. Veterinarni Medicina. 2018;63(4):175-80.

5. Loynachan AT. Eosphageal cyst in the duodenum of a foal. J Vet Diagn Invest. 2014;26(2):308-11.

6. Peek SF, DeLahunta A, Hackett RP. Combined oesophageal and tracheal duplication cyst in an Arabian filly. Equine Vet J. 1995;27(6):475-8.

7. Orsini JA, Sepesy L, Donawick WJ. Esophageal duplication cyst as a cause of choke in the horse. J Am Vet Med Assoc. 1998;193(4):474-6.

8. Doran ICP, Dawson LJ, Costa M. Surgical Resolution of an esophageal duplication cyst causing regurgitation in a domestic shorthair cat. Journal of Feline Medicine and Surgery Open Reports. 2015;1 (2):2055116915623799.

9. Okazaki Y, Matsumota M, Tsubota K. Foregut cyst of the esophageal wall in a cynomolgus monkey (Macaca fascicularis). J Comp Path. 2016;135(4):256-62.

10. Sinha CK, Nour S, Fisher R. Pyloric duplication in the newborn: A rare cause of gastric outlet obstruction. JIAPS. 2007;12(1):34-5.

11. Grosfeld JL, Boles ETJR, Reiner C. Duplication of pylorus in the newborn: A rare cause of gastric outlet obstruction. J Pediatr Surg. 1970;5(3):365-9.

12. Saad DF, Gow KW, Shehata B, Wulkan ML. Pyloric duplication in a term newborn. J Pediatr Surg. 2005;40(7):1209-10.

13. Hamada Y, Inoue K, Hioki K. Pyloroduodenal duplication cyst: Case report. Pediatr Surg Int. 1997;12(2-3):194-5.

14. Martin ND, Kim JC, Verma SK, Rubin R, Mitchell DG, Bergin D, et al. Intraabdominal esophageal duplication cysts: A review. J Gastrointest Surg 2007;11(6):773-7.

15. Bremer J. Diverticula and duplications of the intestinal tract. Arch Pathol. 1994:38:132-40

16. Yeung C, MacDonald B, Gilbert S. 'Esophageal Duplication Cyst' Yeo CJ Shackelford's surgery of the alimentary tract. Philadelphia, PA: Elsevier/Saunders. 2017;490-491

17. Sonthalia, et al. Congenital Esophageal Duplication Cyst: A Rare Cause of Dysphagia in an Adult. Gastroenterol Res. 2016;9(4-5):79-82.

18. Murty TV, Bhargava RK, Rakas FS. Gastroduodenal duplications. J Pediatr Surg. 1992;27(4):515-7.

19. Adams DB, Morgan KA, Yeo CJ. 'Miscellaneous Benign Lesions and Conditions of the Stomach, Duodenum and Small Intestine'. Shackelford's surgery of the alimentary tract. Philadelphia, PA: Elsevier/Saunders. 2017;767.

20. King JE. Seals of the World. Oxford, Oxford University Press. 1983.

21. Coulson, J. D. The growth of grey seal, Halichoerus grypus (Fab), calves on the Farne Islands, Northumberland. Transactions of the Natural History Society of Northumberland. 1959;13:86-100

22. Coulson, JD, Hickling G. The breeding biology of the grey seal Halichoerus grypus (Fab) on the Farne islands, Northumberland. Journal of Animal Ecology. 1964;33:485-512.

23. Reilly JJ. Adaptations to prolonged fasting in free-living weaned grey seal pups. American Journal of Physiology. 1991;260(2):267-72.

24. Osinga N, ShahiFerdous MM, Morick D, GarciaHartmann M, Ulloa JA, Vedder $\mathrm{L}$, et al. Patterns of Stranding and Mortality in Common Seals (Phoca vitulina) and Grey Seals (Halichoerus grypus) in The Netherlands between 1979 and 2008. Journ Comp Path. 2012;147(4):550-65.

25. Siebert U, Wohlsein P, Lehnert K, Baumgärtner W. Pathological findings in harbour seals (Phoca vitulina): 1996-2005. J Comp Pathol. 2007;137(1):47-58. doi: 10.1016/j.jcpa.2007.04.018

26. Trupkiewicz JG, Gulland FM, Lowenstine LJ. Congenital defects in northern elephant seals stranded along the central California coast. J Wildl Dis. 1997:33(2):220-5

27. Spraker TR, Landers ME. Causes of mortality in northern fur seals (Callorhinus ursinus), St. Paul Island, Pribilof Islands, Alaska, 1986-2006. J Wild Dis. 2010;46(2):450-73. 